\title{
Avoiding false positive diagnoses of motor neuron disease: lessons from the Scottish Motor Neuron Disease Register
}

\author{
R J Davenport, R J Swingler, A M Chancellor, C P Warlow on behalf of the Scottish
} Motor Neuron Disease Research Group

\begin{abstract}
Objectives-To describe the frequency and characteristics of those patients initially registered with the Scottish Motor Neuron Disease Register (SMNDR) but who subsequently had a diagnosis other than MND made (false positives), to analyse the features which led to a revised diagnosis, and to draw conclusions which might improve routine neurological practice.
\end{abstract}

Methods-The Scottish Motor Neuron Disease Register is a community based, prospective disease register to identify and follow up all incident cases of motor neuron disease in Scotland. Fifty three patients out of a total of 552 registered are presented, who, after initial registration, were later excluded because they failed to satisfy the register's diagnostic criteria. Results-Seven of these patients were labelled as "MND plus" syndromes and may represent a distinct subset of $M N D$. The remaining 46 patients had an alternative diagnosis made (false positive group), accounting for $8 \%$ of the total. In half of these cases, potentially beneficial therapies are available. The predominant reasons which lead to a diagnostic revision were: failure of symptom progression, development of atypical clinical features for MND, and investigation results.

Conclusions-Patients with MND should undergo thorough and relevant investigations at presentation with the emphasis on neuroradiological imaging and neurophysiology; all patients should be followed up by an experienced neurologist, particularly those in whom symptoms and signs are restricted to either the bulbar or spinal muscles; failure of symptom progression or development of atypical features should lead to an early reassessment; finally, patients should be informed of the diagnosis only when it is secure.

(F Neurol Neurosurg Psychiatry 1996;60:147-151).

Keywords: motor neuron disease; amyotrophic lateral sclerosis; epidemiology; diagnosis

An accurate diagnosis is an essential component of the art of medicine; it enables doctors to make decisions concerning subsequent management and, most importantly from a patient perspective, provides prognostic information. Diseases with either a pathognomic appear- ance or a definitive investigation result should be the most straightforward to diagnose although abnormal variants may pose difficulties. Unfortunately, neurological practice has few definitive investigations and the clinical appearances may be difficult to precisely categorise into specific disease syndromes. Motor neuron disease (MND) presenting with a classic history and signs, supported by consistent neurophysiology, should rarely cause the experienced neurologist diagnostic doubt. However, many patients present less obviously and patients with other diagnoses may seem to have the features of MND. Yet an accurate and perhaps early diagnosis of MND is crucial for three reasons. Firstly, the appalling prognosis is of the utmost importance to both the patient and their carers (overall 50\% survival from symptom onset for our patients was 2.5 years). ${ }^{1}$ Secondly, potentially treatable diseases that mimic MND, such as cervical spondylotic myelopathy or multifocal motor neuropathy, must be identified to allow appropriate therapy. Thirdly, although no effective treatment for MND currently exists, one recent therapeutic trial reported encouraging results. ${ }^{2}$ Further trials are inevitable and it will be important to correctly diagnose MND early to identify suitable patients for inclusion in randomised trials. If these trials provide convincing evidence for a specific treatment, an early and accurate diagnosis will become even more important for all patients with MND.

The purpose of this paper is to describe the frequency and characteristics of those patients initially registered with the Scottish Motor Neuron Disease Register (SMNDR) but who subsequently had a diagnosis other than MND made (false positives), to analyse the features which led to a revised diagnosis, and to draw conclusions which might improve routine neurological practice.

\section{Methods}

The SMNDR was established in January 1989 with the aim of studying the incidence, distribution, clinical features, and prognosis of MND in Scotland, and as a resource for other research. The methods of the study are described in detail elsewhere. ${ }^{34}$ Briefly, all incident cases (patients in whom a diagnosis of MND was first made after January 1989) of possible, probable, or definite $\mathrm{MND}$ in Scotland were identified and then followed up at six monthly intervals via their general practitioner until either death or an alternative diagnosis was made. The following sources of 
patient identification were used to allow as complete case ascertainment as possible: the study collaborators (including all the consultant neurologists and neurophysiologists in Scotland); an annual mailshot to all general practitioners in Scotland enquiring about cases known to them; the Scottish Motor Neuron Disease Association family care officers and self referrals; an annual list of all patients appearing in the Scottish Hospital InPatient Statistics (SHIPS) coded with the International Classification of Diseases (ICD) 9 code 335 (anterior horn cell disease); neuropathology departments; and an annual list of deaths whenever ICD-9 code 335 appeared on the death certificate. All patients notified by a collaborator or a neuropathologist were automatically registered. In all other cases, the hospital and/or general practice records were requested and perused. This was to exclude prevalent cases (those diagnosed before January 1989) and to avoid the problems of inaccurate coding, the extent of which we have reported on previously. ${ }^{5}$ Patients who had not seen a collaborator, and in whom a diagnosis of MND had been made but who had features clearly incompatible with the diagnosis, were also excluded at this stage. In common with many disease registers, we encouraged early registration, even if the diagnosis was only of possible $M N D$.

When the register was started, there were no universally accepted criteria for the diagnosis of MND; therefore we devised a set of simple but specific criteria suitable for applying to an epidemiological rather than a hospital based study. The criteria were as follows: any adult ( $>15$ years) onset progressive motor system disorder (sporadic or familial)-divided into two further categories, clinically definite and clinically probable, the criteria for which are described in detail elsewhere. ${ }^{3}$ Briefly, definite cases required a combination of upper and lower motor neuron signs involving the brainstem and one or more spinal regions. Probable cases included patients with (a) a combination of upper and lower motor neuron signs restricted to the brainstem or spinal regions and (b) patients with exclusively lower or exclu- sively upper motor neuron signs. All cases required the following features: a progressive course, absence of sensory signs, sphincteric disturbance, parkinsonism, dementia, and causes of syndromes which may mimic MND.

Patients in whom an alternative diagnosis was made at any stage after registration, or who developed features incompatible with the above definitions, were excluded from further follow up. It was not practicable to develop a list of diagnostic criteria for all these alternative diagnoses so we relied on the clinical impression and diagnosis made by the individual clinicians responsible for the patients.

\section{Results}

A total of 552 potential incident cases for the period January 1989 to December 1992 were registered. Six of these patients were subsequently deleted from the database as they turned out to be prevalent cases of MND. A further $53(10 \%)$ were excluded as "not MND" and are the subjects of this report. Thirty six $(68 \%)$ were men, median age 64.5 (range 36-84) years. The sources of first referral were a collaborator (39), SHIPS (six), general practitioner mailshot (five), self referral (two), and mortality data (one). Only seven of these 53 patients were never seen by a neurologist; six of them were registered by a collaborator, either a neurophysiologist or a physician, with a special interest in MND.

At the time of registration 34 (64\%) patients had a suggested alternative diagnosis. The regions involved at registration were the bulb only in two patients (4\%), limbs only in 38 patients $(72 \%)$, and both regions in 11 patients $(21 \%)$; in two patients the regions involved were uncertain.

Table 1 shows the revised diagnoses. In seven patients a diagnosis of "MND plus" was made; these patients had clinical features compatible with MND but also displayed additional abnormalities which led to their exclusion; these were dementia (three), cerebellar disturbance (two), parkinsonism (one), and retinitis pigmentosa with slowed nerve conduction velocities (one); in none of these

Table 1 Revised diagnoses and features leading to reassessment

\begin{tabular}{|c|c|c|c|c|}
\hline \multirow[b]{2}{*}{ Revised diagnosis } & \multirow[b]{2}{*}{$\begin{array}{l}\text { No of } \\
\text { patients }\end{array}$} & \multicolumn{3}{|c|}{ Primary feature leading to revised diagnosis } \\
\hline & & $\begin{array}{l}\text { Atypical } \\
\text { clinical features } \\
\text { for MND }\end{array}$ & $\begin{array}{l}\text { Investigation } \\
\text { result }\end{array}$ & $\begin{array}{l}\text { Failure to } \\
\text { progress }\end{array}$ \\
\hline $\begin{array}{l}\text { Cervical spondylotic myeloradiculopathy } \\
\text { "MND plus" syndromes }\end{array}$ & $\begin{array}{r}10 \\
7\end{array}$ & 7 & 4 & 6 \\
\hline Cerebrovascular disease & 5 & 1 & & 4 \\
\hline Radiculopathy of unknown cause & 4 & & & 4 \\
\hline Probable multiple sclerosis & 4 & 3 & 1 & \\
\hline Multiple system atrophy & 4 & 4 & & \\
\hline Peripheral neuropathy of unknown cause & 4 & 2 & 2 & \\
\hline Multifocal motor neuropathy & 2 & & 2 & \\
\hline Brachial neuritis & 1 & & & 1 \\
\hline Polymyositis & 1 & & 1 & \\
\hline Normal pressure hydrocephalus & 1 & & 1 & \\
\hline Retropharyngeal tumour & 1 & 1 & & \\
\hline Ulnar neuropathy & 1 & & & 1 \\
\hline Cervical meningioma & 1 & 1 & & \\
\hline Benign fasciculation & 1 & & & 1 \\
\hline Cranial nerve palsy of unknown cause & 1 & & & 1 \\
\hline Lumbar stenosis & 1 & & & 1 \\
\hline Uncertain & 4 & & & 4 \\
\hline Totals & 53 & $19(36 \%)$ & $11(21 \%)$ & $23(43 \%)$ \\
\hline
\end{tabular}


Table 2 Necropsy data on five patients

\begin{tabular}{ll}
\hline Diagnosis at death & Pathological data \\
\hline 1 MND plus dementia & $\begin{array}{c}\text { Features compatible with MND plus frontal lobe neuronal loss and reactive } \\
\text { gliosis }\end{array}$ \\
2 MND plus dementia & $\begin{array}{l}\text { Features compatible with MND; no cause for dementia demonstrated } \\
\text { Features compatible with MND; no cause for dementia demonstrated } \\
4 \text { Peripheral neuropathy of unknown cause } \\
\text { Systemic lymphoma (probably T cell); no evidence of infiltration of central/ } \\
\text { peripheral nervous system. Evidence of anterior horn cell loss localised to } \\
\text { C8 level only }\end{array}$ \\
$\begin{array}{c}\text { Longstanding cerebrovascular disease; spinal cord normal. Peripheral nervous } \\
\text { system not examined }\end{array}$ \\
\hline
\end{tabular}

patients was there a known family history of relevant neurological disease.

Fifteen patients (28\%) are known to have died (this is likely to be an underestimate as follow up stopped once an alternative diagnosis was reached). Of these, five had necropsies, including detailed neuropathological examinations. Table 2 shows the results. Both patients with a premorbid diagnosis of peripheral neuropathy had undergone neurophysiological testing; in patient 4 this showed evidence of neuronal loss restricted to the C8/T1 level. This was confirmed at necropsy but no cause was identified; he had continued to weaken before death but there do not seem to have been any symptoms related to his lymphoma. Case 5 had widespread neurophysiological evidence of motor neuronal loss which was suggestive but not diagnostic of MND; on his final admission he had not progressed neurologically and a history of alcohol misuse was obtained for the first time. He died suddenly of ischaemic heart disease; although the peripheral nervous system was not examined, there was no evidence of MND in the brain or spinal cord.

We analysed the factors which led to a diagnostic revision and found that there were three predominant reasons, shown in table 1 . A failure to progress (and even recovery) was the commonest, prompting reassessment in almost $50 \%$. The development of atypical features (for MND) and the results of investigations were the primary reasons in the remaining patients; radiological imaging and neurophysiology led to a revised diagnosis in equal numbers of patients.

\section{Discussion}

Seven patients were labelled as "MND plus" syndromes - that is, in addition to a clinical syndrome compatible with MND, they had features which led to their exclusion according to the SMNDR's diagnostic criteria. This distinction may seem arbitrary and it has been suggested that these patients may represent a continuum of MND, particularly those with associated dementia. ${ }^{67}$ The neuropathological data from three of the patients seem to support this notion; although only one displayed the characteristic frontal lobe changes previously described, ${ }^{6}$ all three had the typical pathological appearances of MND. Careful review of the case notes of the remaining four patients, all of whom were cared for by a neurologist, showed that in each case the diagnosis was considered to be MND in addition to the extra features, rather than a unifying diagnosis such as multiple system atrophy. In all four of the patients with multiple system atrophy the diagnosis was made by a neurologist; the additional features were extrapyramidal in three, cerebellar in three, and sphincteric in one. Three had upper motor neuron and lower motor neuron signs, the other purely upper motor neuron signs; three had undergone neurophysiological tests and the results were considered compatible with MND. It is reasonable to question whether these patients should not simply be included in the "MND plus" group but the clinicians clearly thought that the upper and lower motor neuron signs in these four patients were part of a multisystem degeneration; this difference may simply reflect nosological differences between neurologists. However, it seems that the seven "MND plus" patients are better categorised as a distinct subset of MND rather than false positive diagnoses. Excluding these seven patients reduces the proportion of false positive diagnoses to $8 \%$.

Do our results accurately reflect the frequency of the problem? The number of false positives (the numerator) pertains mainly to patients with whom a neurologist was involved. Only seven patients never saw a neurologist at any point in their illness (although six underwent neurophysiological tests). The diagnoses in these patients were normal pressure hydrocephalus with a sensorimotor neuropathy of unknown cause, retropharyngeal tumour, cervical meningioma, cervical spondylotic myelopathy, peripheral neuropathy of unknown cause, and two patients in whom the diagnosis was uncertain. We did not register patients identified by SHIPS, mortality data, self referrals, or as a result of the general practitioner mailshot in whom, although the diagnosis was considered correct by the clinicians involved, perusal of hospital and/or general practitioners' notes disclosed features clearly incompatible with MND; none of these patients had been seen by a neurologist and few had undergone relevant investigations. Hence our results cannot be attributed to misdiagnoses by non-specialists. Because of the design of the register we are confident that the denominator is as complete as possible. Thus we think that $8 \%$ is an accurate reflection of the frequency of false positive diagnoses for MND in specialist practice, at least in Scotland.

Were all the false positives definite misdiagnoses? We deliberately encouraged collaborators to register patients as early as possible, 
regardless of whether they thought that the diagnosis of MND was possible, probable, or definite. Clearly the point at which an individual collaborator registered a patient varied considerably but a high proportion (64\%) of the false positive group had an alternative diagnosis suggested at the time of registration; also only three patients fulfilled the criteria for definite MND (upper and lower motor neuron signs in the bulb and one or more spinal regions) at the time of registration. This suggests that many of the cases were not definite misdiagnoses but rather that MND was part of a differential diagnosis; however, in 15 out of $46(33 \%)$ patients the diagnosis of MND was considered secure enough to allow the clinician to inform the patient. As might be expected, the revised diagnoses were, with one or two exceptions, well recognised mimics of MND. It should be noted that potential treatments, either surgical or medical, are available for about half of the non-MND patients, underlining the importance of an accurate diagnosis.

Can we be sure that all these patients definitely did not have MND and how reliable are the alternative diagnoses? Although the decision to exclude a patient from the register and cease further follow up was made by ourselves, we were dependent on the information received from the collaborator or general practitioner caring for the patient. Therefore, the exclusions were all based on the clinical impressions of the responsible physicians, who were usually neurologists; we did not have specific diagnostic criteria for these alternative diagnoses (indeed for many of them, no universally accepted criteria exist). In a few patients, the alternative diagnosis was established histologically (for example, cervical meningioma) and some patients spontaneously improved; clearly these patients definitely did not have MND. But could some of the other diagnoses (for example, cervical spondylotic myeloradiculopathy) have been incorrect and how convincing was the evidence? Of the 10 cases of cervical spondylotic myeloradiculopathy, a neurologist was involved in the care of nine and eight had radiological imaging which their neurologist thought was compatible with cervical spondylotic myeloradiculopathy (the remaining patients improved spontaneously and hence were not imaged). Eight of the patients had upper and lower motor neuron signs at the time of registration and review of the clinic letters suggests that MND was thought to be a likely diagnosis in five and possible in the others. None of these patients had undergone surgery at the time follow up ceased but clearly this may have occurred later. Thus because we have not followed these patients up further, we cannot be sure that cervical spondylotic myeloradiculopathy was the correct diagnosis; however, there was strong circumstantial evidence to support this impression. Finally, because these patients were usually under the care of a collaborator, it is likely that a further diagnostic revision, reverting to MND, would be unusual enough to cause the collaborator to inform us.
Can we identify specific features which lead to diagnostic revision? Failure of the patient to progress was the key factor in nearly half the cases; MND is usually distressingly rapid in its progression and although "resistant" cases are well recognised, ${ }^{18}$ a static or improving clinical state should always stimulate a reappraisal. In some of our cases, the failure to progress led to further investigations which provided a new diagnosis. In the patients in whom investigation results were the key feature it is clear that MND was usually part of a differential diagnosis with clinical features suggesting possible alternative diseases (for example, lack of signs above the neck prompting radiological imaging of the cervical spinal cord); however, neurophysiology was critical in differentiating MND from other motor neuropathies, particularly multifocal motor neuropathy, which may appear clinically very similar to MND. Although rare, this syndrome is treatable, ${ }^{9}$ hence recognition is essential. The importance of continued surveillance of suspected MND is also emphasised by the fact that about a quarter of the patients developed atypical features for $\mathrm{MND}$, resulting in a diagnostic review.

Many neurologists only feel completely secure with a diagnosis of MND when upper and lower motor neuron involvement is shown in both the bulbar and spinal regions, either clinically or by neurophysiology. This is borne out by our study; only $11(21 \%)$ patients in the false positive group had bulbar and spinal involvement at registration and only three of these were thought to have definite upper and lower motor neuron lesions in both regions.

In conclusion, a false positive diagnosis of MND by neurologists is uncommon; however, because of the prognostic implications of a diagnosis of MND, it is an important problem. From the results of our study we suggest the following:

(1) All suspected cases of MND require thorough initial investigation to exclude alternative diseases, with neurophysiology and radiological imaging the most important modalities.

(2) All patients should be followed up wherever practical, particularly those in whom upper and lower motor neuron involvement has yet to affect the bulb and spinal regions. This follow up should be done by consultant neurologists who must be vigilant for either failure of symptom progression or the development of atypical features which should in turn lead to reassessment.

(3) Informing the patient of a diagnosis of MND should normally be withheld until the diagnosis is considered to be completely secure. Clearly there is a balance between keeping patients well informed and providing inaccurate information but, because of the prognostic implications, we advocate a policy of awaiting indisputable evidence of MND.

We are grateful to all the collaborators, a full list of whom appears in an earlier report of the SMNDR. ${ }^{3}$ RJD is funded by a Medical Research Council grant. AMC was funded by the Scottish Motor Neuron Disease Association for part of this work. 
1 Chancellor AM, Slattery JM, Fraser H, Swingler RJ, Holloway SM, Warlow CP. The prognosis of adult-onset motor neuron disease: a prospective study based on the Scottish Motor Neuron Disease Register. F Neurol 1993; 240:339-46.

2 Bensimon G, Lacomblez L, Meininger V, ALS/Riluzole Study Group. A controlled trial of Riluzole in amyotrophic lateral sclerosis. $N$ Engl $f$ Med 1994;330: otrophic

3 The Scottish Motor Neuron Disease Research Group. The Scottish motor neuron disease register: a prospective study of adult onset motor neuron disease in Scotland. Methodology, demography, and clinical features of incident cases in 1989. F Neurol Neurosurg Psychiatry 1992; 55:536-41.

4 Chancellor AM, Davenport RJ, Swingler RJ, Warlow CP. The Scottish Motor Neuron Disease Register: a mode for registers of uncommon diseases in Scotland. Health Bull 1994;52:342-7.
5 Chancellor AM, Swingler RJ, Fraser H, Clarke JA, Warlow CP. Utility of Scottish morbidity and mortality data for epidemiological studies of motor neuron disease. $\mathscr{f}$ Epidemiol Community Health 1993;47:116-20.

6 Neary D, Snowden JS, Mann DMA, Northen B, Goulding PJ, Macdermott N. Frontal lobe dementia and motor neuron disease. $\mathcal{F}$ Neurol Neurosurg Psychiatry 1990;53: 23-32.

7 Talbot PR, Goulding PJ, Lloyd J, Snowden JS, Neary D, Testa HJ. Inter-relation between "classic" motor neuron disease and frontotemporal dementia: neuropsychological and single photon emission computed tomography study. F Neurol Neurosurg Psychiatry 1995;58:541-7.

8 Mulder DW, Howard FM. Patient resistance and prognosis in amyotrophic lateral sclerosis. Mayo Clin Proc 1976;51 $537-41$.

9 Chaudhry V, Corse AM, Cornblath DR, et al. Multifocal motor neuropathy: response to human immune globulin. Ann Neurol 1993;33:237-42

\section{Historical note on the therapeutic use of botulinum toxin in neurological disorders}

In recent years the type $\mathrm{A}$ neurotoxin of Clostridium botulinum has been successfully used for the treatment of conditions caused by focal hypercontractions of skeletal muscles (such as strabismus, hemifacial spasm, focal dystonias, and spasticity) or smooth muscles (such as achalasia). ${ }^{123}$ Symptomatic therapeutic chemodenervation was pioneered by Alan B Scott. ${ }^{4}$ Surprisingly, the idea for therapeutic use of botulinum toxin was developed 160 years before Scott's report by the German physician and poet Justinus Kerner (1786-1862). Kerner published the earliest systematic descriptions on the clinical features of foodborne botulism in 1817 in the Tübinger Blätter für Naturwissenschaften und Arzneykunde (Tübinger papers for natural sciences and pharmacology). ${ }^{5}$ Subsequently, Kerner published two monographs about botulism, in 1820 and 1822. His second monograph reviewed 155 cases of poisoned patients and was entitled Das Fettgift oder die Fettsäure und ihre Wirkungen auf den thierischen Organismus, ein Beytrag zu den in verdorbenen Würsten giftig wirkenden Stoffes (The fat poison or the fatty acid and its effects on the animal organism, a contribution to the substance which acts toxically in sausages) ${ }^{6}$ Kerner considered that a toxic substance in sausages, which he called "fatty acid", was responsible for neuromuscular paralysis. One chapter was entitled Über die Fettsäure als mögliches Heilmittel (About the fatty acid as a possible therapeutic drug). In this chapter he wrote (pp 337-50):

"Die Fettsäure oder zoonische Säure, in solchen Gaben gereicht, daß ihre Wirkung auf die Sphäre des sympathischen Nervensystems hauptsächlich beschränkt bliebe, möchte in den vielen Krankheiten, die aus Aufreizung dieses Systems entstehen, von Nutzen seyn" ("The fatty acid or zoonic acid administered in such doses, that its action could be restricted to the sphere of the sympathetic nervous system only, could be of benefit in the many diseases which originate from hyperexcitation of this system"). Kerner considered St Vitus's dance a possible indication for this treatment. Later in the monograph Kerner wrote: "Was aber hier über die Fettsäure als mögliches Heilmittel geäußert wurde, gehört allerdings nur in das Reich der Hypothesen, und kann nur von dereinstigen Beobachtungen bestätigt oder widerlegt werden" ("What is said here about the fatty acid as a therapeutic drug belongs to the realm of hypotheses and may be confirmed or disproved by observations in the future"'). Fortunately, Kerner's early vision has been realised by the work of Alan B Scott and by subsequent and ongoing clinical research on the therapeutic use of botulinum toxin in neurological disorders.

$$
\begin{array}{r}
\text { FRANK J ERBGUTH } \\
\text { Department of Neurology, } \\
\text { University of Erlangen-Nuremberg, } \\
\text { Schwabachanlage 6, } \\
\text { D-91054 Erlangen, Germany }
\end{array}
$$

1 American Academy of Neurology. The clinical usefulness of botulinum toxin $\mathrm{A}$ in treating neurologic disorders. Neurology 1990;40:1332-6.

2 Jankovic J, Schwartz K, Donovan D. Botulinum toxin treatment of cranial-cervical dystonia, spasmodic dysphonia, other focal dystonias and hemifacial spasm. $f$ Neurol Neurosurg Psychiatry 1990;53:633-9.

3 Pasricha PJ, Ravich WJ, Hendrix TR, Sostre S, Jones B, Kaloo AN. Intrasphincteric botulinum toxin for the Kaloo AN. Intrasphincteric botulinum toxin for the

4 Scott AB. Botulinum toxin injection of eye muscles to correct strabismus. Trans Am Ophthalmol Soc 1981;79:
(1) 734-70.

5 Kerner J. Vergiftung durch verdorbene Würste. Tübinger Blätter für Naturwissenschaften und Arzneykunde 1817:3: $1-25$.

6 Kerner J. Das Fettgift oder die Fettsäure und ihre Wirkungen auf den thierischen Organismus, ein Beytrag zur Untersuchung des in in verdorbenen Würsten giftig wirkenden Stoffes. Stuttgart, Tübingen: Cotta, 1822. 